\title{
Mammograms and breast arterial calcifications: looking beyond breast cancer: a preliminary report
}

\author{
Rachael A Akinola ${ }^{1 *}$, Okeoghene A Ogbera ${ }^{2 \dagger}$, Josephine AA Onakoya ${ }^{3 \dagger}$, Chris E Enabulele ${ }^{4 \dagger}$ and \\ Idowu O Fadeyibi ${ }^{5 \dagger}$
}

\begin{abstract}
Background: To find out the prevalence, clinical and biochemical correlates of Breast Artery Calcification (BAC) in the Nigerian women.

Findings: This is a cross sectional study involving 54 consecutive adult female subjects sent to the Radiology Department of the Lagos State University Teaching Hospital (LASUTH), Ikeja-Lagos, Nigeria for screening and diagnostic mammography. The study was carried out for a period of five months.

The prevalence of BAC was 20\%. Ageing was found to be related to BAC. Cardiovascular risk factors including diabetes mellitus (DM), hypertension, obesity, alcohol ingestion, use of oral contraceptives and hormone replacement therapy, were not significantly related to the presence of BAC in this study.
\end{abstract}

Conclusion: This study showed that though the presence of BAC in a mammogram is related to age, it may not predict or serve as a significant marker for cardiovascular diseases (CVD) in women in our environment.

\section{Background}

Arterial calcification is a common feature of atherosclerosis which can be elicited with conventional radiological imaging as calcium deposits in the arterial wall [1]. The appearance of calcium in different vascular beds occurs 10-15 years later in women than in men [1]. Breast Artery Calcification (BAC) on mammography was seen in $9 \%$ of women in a study that was carried out in Utrecht, The Netherlands. BAC has been identified as calcific medial sclerosis of medium sized breast arteries and was reported to be associated with cardiovascular risk factors including diabetes mellitus [DM], hypertension [2], coronary artery disease (CAD) and cardiovascular mortality [1,3-6].

Histopathologically, medial calcification differs from intimal calcification in the absence of signs of inflammation and lipid deposits $[1,7]$. Conventional $\mathrm{x}$-ray techniques cannot however differentiate between intimal and

\footnotetext{
* Correspondence: adeyanjuakinola@yahoo.com

† Contributed equally

'Department of Radiology, College of Medicine/Lagos State University

Teaching Hospital (LASUTH), Ikeja- Lagos, Nigeria

Full list of author information is available at the end of the article
}

medial calcification. Medial calcification is finer and diffuse in smaller vessels, while intimal thickening in large and medium sized arteries, are large and discontinuous $[1,3,7]$. Atherosclerosis and medial sclerosis appear more frequently and at an earlier age in diabetic patients [8]. Fiuza et al [9] suggested that mammographic finding of BAC calls for more attention from the Radiologist and should not be excluded from reports.

Vascular calcifications in the breast are defined as the presence of parallel linear calcified deposits along the course of a vessel that is seen on at least one view of a mammogram $[7,10]$. They are called Monckeberg calcifications and involve the middle layer of arteries $[3,7,10]$. They are diffuse, thin and involve the whole circumference of the peripheral arteries making the vessels stiff. These are uncommon in patients less than 50 years old and are found in about $9.1 \%$ mammograms $[2,3,7,10,11]$. The prevalence of vascular calcification ranges from 9$17 \%$ and increases with age, exceeding $50 \%$ in women aged 65 years and above $[10,12]$. Other studies have found associations between $\mathrm{BAC}$ and chronic diseases including kidney failure, autonomic neuropathy and hypervitaminosis D [10] and also with Cardiovascular

\section{() Biomed Central}


risk factors which include increasing age, parity, obesity, cigarette smoking, alcohol ingestion, use of oral contraceptives or hormone replacement therapy, diabetes, hypertension and deranged lipid profile [2].

$\mathrm{BAC}$ that is seen in breast cancer screening mammograms may also be associated with disorders related to increased or accelerated atherosclerosis [13]. Increased parity has been associated with decrease in breast cancer risk but increases the occurrence of BAC [13]. Breast cancer screening may also aid early detection of enhanced CVD risk among otherwise healthy women [13].

This study is aimed at finding the prevalence of BAC and its relationship with cardiovascular (CVD) risk factors in Lagos, Nigeria.

\section{Methods}

Fifty-four consecutive adult female subjects that were sent for screening and diagnostic mammography between February and June 2010 were recruited for this prospective study. All the subjects consented to the study. Interviewer administered questionnaire which included information on the biodata and anthropometric measurements comprising of waist circumference, height and body weight were answered by the patients. The Body Mass Index (BMI) was calculated using the formula- weight $/$ height ${ }^{2}\left(\mathrm{~kg} / \mathrm{m}^{2}\right)$ for the patients [10]. The waist circumference was measured at the midpoint between the inferior margin of the 10th rib and the crest of the ilium with a tape measure. The medical history of any previous stroke and or heart failure and necessary information on the risk factors for CVD were also obtained.

The mammograms, cephalocaudal (CC) and mediolateral oblique (MLO) views were done using a Villa Systemi Stereotactic Mammography machine and these were assessed for BAC using a well illuminated viewing box and hand lens.

An excel data spreadsheet was used to record all these information. Statistical Package for Social Sciences (SPSS), version 17, Chicago Illinois was used for statistical analysis

\section{Statistical Analyses}

Descriptive results for continuous variables were expressed as mean \pm standard deviation (SD). Biochemical and clinical parameters were compared between the study subjects with and without BAC using independent samples t-test for continuous variables and chi-square for categorical data. Possible predictors for the presence of BAC were evaluated using binary logistic regression. The variables entered in the model included CVA risk factors (obesity, central obesity, elevated LDL, elevated total cholesterol and dyslipidaemia). A p-value $<0.05$ was considered statistically significant.

\section{Biochemical analyses}

\section{Lipid parameters}

Fasting venous blood samples were taken for the determination of High Density Lipoprotein-Cholesterol (HDL-C), and Triglyceride (TG). HDL-C was determined by the precipitation method [14] and TG estimated using a standardized kit employing enzymatic hydrolysis of TG with lipases [15]. Fasting Blood Sugar (FBS) level estimation was done as a point of care test using a glucometer (Glucolab manufactured by Infopia Limited, Korea Republic) from fasting capillary blood samples. Total cholesterol (TCHOL), Low density Lipoprotein Cholesterol (LDL-C), Very Low Density Lipoprotein (VLDL) and electrolyte and urea (E\&U) were also assessed. The serum levels of Total protein and albumin were also checked.

\section{Operational definitions}

1. Abnormal lipid parameters refers to elevated TCHOL, LDL, TG and reduced HDL [16].

2. Dyslipidaemia refers to serum triglycerides (TG) level of at least $150 \mathrm{mg} / \mathrm{dl}$, high-density lipoprotein cholesterol (HDL-C) level of less than $50 \mathrm{mg} / \mathrm{dl}$ [17].

3. Hypercholesterolaemia and elevated LDL refers to TCHOL > $200 \mathrm{mg} \%$ and LDL-C > $100 \mathrm{mg} \%$ [16].

4. Obesity was defined as abnormal or excessive fat accumulation that may impair health. Obesity refers to a BMI >to 30 [18].

5. Central obesity was when the waist circumference (WC) dimension was greater than $88 \mathrm{~cm}$ [17].

6. BAC was diagnosed when easily recognized characteristic pattern of two linear parallel calcific lines giving a "railroad track" configuration described by Sickles was seen on the mammogram $[3,7,10,19]$, (Figure 1).

\section{Results}

This study revealed that the older the patient, the more the possibility of developing BAC, as shown in (Table 1). Most of the BAC seen in this study occurred between $60-69$ years while none was seen below 40 years, (Table 1).

Only six (11.15\%) participants had a significant history of alcohol ingestion, none of them smoked cigarette and none had a past or present history of cardiovascular accident (CVA) or heart failure. The potential risk factors for BAC in the study subjects are shown in (Table 2).

About one fifth of the study subjects had BAC, with a prevalence of $20 \%$ and of all the correlates, only the difference in the ages of subjects with and without BAC was statistically significant $(\mathrm{p}=0.002)$,(Table 3$)$. Those that had BAC were obese with an average BMI of 31.3 $\mathrm{Kg} / \mathrm{m}^{2}$ though not statistically significantly different from those that did not have BAC. Their fasting blood 

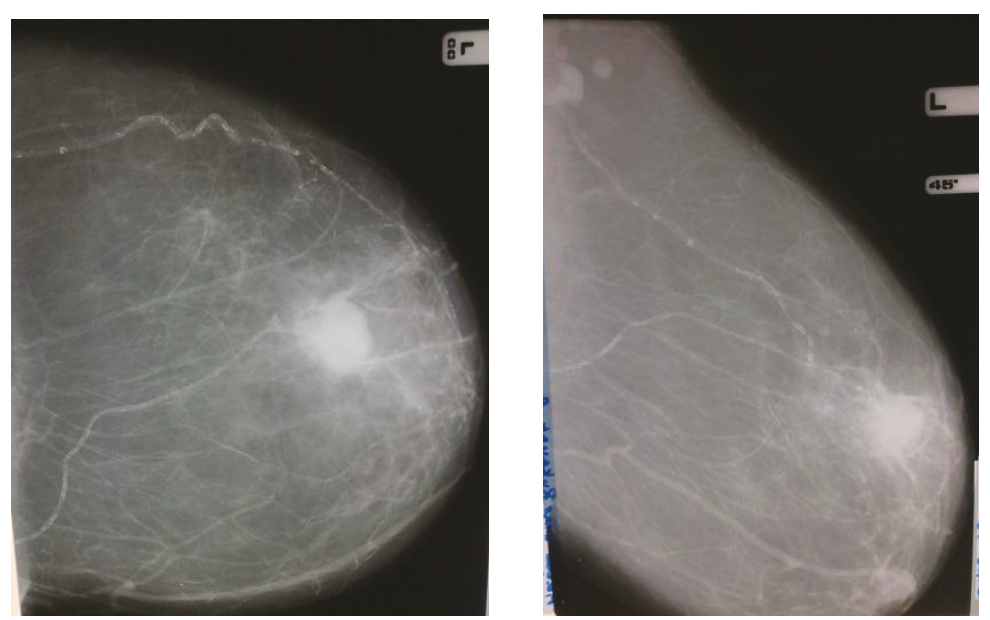

Figure 1 Showing the CC and MLO views of a mammogram with "Tram-like calcifications" in the upper quadrant of the breast in an 80 year old woman who incidentally also had a malignant breast mass.

sugar was however within normal limits. All the clinical and biochemical correlates were not statistically significant, (Table 3).

Table 3 also shows that although the mean age of the subjects with BAC was significantly higher than the subjects without $\mathrm{BAC}$, all other mean values of their clinical and biochemical parameters were comparable.

The distribution of CVD risk factors were similar in subjects with and without BAC and Figure 2 shows that apart from the elevated total cholesterol, the proportion of subjects with BAC who had the CVD risk factors depicted in the figure was less than $50 \%$.

Of the 34 subjects who were menopausal, only 3 $(8.8 \%)$ were found to have vascular calcifications, and the difference in the occurrence of BAC in subjects with or without history of the use of oral contraceptives was not statistically significant $(\mathrm{p}=0.09)$. Only One subject among those with history of the use of HRT had vascular calcification and there was no statistically significant difference in the occurrence of vascular calcifications

Table 1 Distribution of BAC according to age decades in the study subjects

\begin{tabular}{lccc}
\hline $\begin{array}{l}\text { Age Range } \\
\text { (years) }\end{array}$ & $\begin{array}{c}\text { Subject } \\
\text { Fequency (\%) }\end{array}$ & $\begin{array}{c}\text { BAC } \\
\text { Frequency } \\
(\%)\end{array}$ & $\begin{array}{c}\text { BAC Frequency/Subject } \\
\text { frequency (\%) }\end{array}$ \\
\hline $\mathbf{3 0 - 3 9}$ & $1(1.9)$ & $0(0)$ & $0 \%$ \\
$\begin{array}{l}\mathbf{4 0}-\mathbf{4 9} \\
\text { years }\end{array}$ & $20(37.0)$ & $2(18.2)$ & $10 \%$ \\
$\mathbf{5 0}-\mathbf{5 9}$ & $21(38.9)$ & $2(18.2)$ & $9.5 \%$ \\
years & $10(18.5)$ & $5(45.5)$ & $50 \%$ \\
$\begin{array}{l}\mathbf{6 0}-\mathbf{6 9} \\
\text { years }\end{array}$ & $2(3.8)$ & $2(18.2)$ & $100 \%$ \\
$>\mathbf{7 0}$ years & & &
\end{tabular}

among the subjects with and without history of usage of HRT ( $=0.7)$. Vascular calcification was not found in any of the participants with a history of alcohol ingestion or DM, while all except $2(18,2 \%)$ of the subjects with BAC breast fed. This study has therefore shown that none of the possible predictors of BAC that were investigated was statistically significant, (Table 4).

\section{Sites of BAC}

BAC was found in $5(45.5 \%)$ breasts on the right and 2 $(18.2 \%)$ on the left. It occurred bilaterally in $4(36.4 \%)$. Two (18.2\%) of those that had BAC were nulliparous. All the quadrants of the breasts were equally affected (upper, 36.4\%, lower, 36.4\% and upper and lower, $27.2 \%)$.

\section{Discussion}

The significance of BAC on mammograms is still debatable. While some authors claim that it might be a useful means of predicting CVD in women, others are of contrary opinion $[1,8,12,19]$.

\section{Table 2 Distribution of some risk/potential factors for}

\section{BAC}

\begin{tabular}{ll}
\hline Parameter & No. (Frequency)\% \\
\hline Breast Feeding & $48(89 \%)$ \\
Hypertension & $19(35 \%)$ \\
DM & $5(9 \%)$ \\
History of usage of oral contraceptive & $10(18 \%)$ \\
History of use of hormone replacement therapy & $4(8 \%)$ \\
Alcohol ingestion & $6(11,1 \%)$ \\
Menopausal status & $34(62 \%)$ \\
\hline
\end{tabular}


Table 3 Comparison of clinical and biochemical variables between the subjects with and without BAC

\begin{tabular}{cccc}
\hline Variables & Subjects with BAC & Subjects without BAC & p value \\
\hline Age (years) & $60(10.1)$ & $50.9(7.8)$ & 0.002 \\
BMI $\left(\mathrm{Kg} / \mathrm{m}^{2}\right)$ & $31.3(4.9)$ & $28(4.9)$ & 0.09 \\
WC $(\mathrm{cm})$ & $93.5(10.6)$ & $93.4(17.5)$ & 0.9 \\
Weight $(\mathrm{Kg})$ & $78.9(11)$ & $73.7(13.5)$ & 0.2 \\
T chol $(\mathrm{mg} \%)$ & $177.4(32.9)$ & $178.4(36.9)$ & 0.1 \\
TG $(\mathrm{mg} \%)$ & $79(28.2)$ & $65.7(22.5)$ & 0.3 \\
HDL-C (mg\%) & $50(9)$ & $45.7(14.3)$ & 0.6 \\
LDL-C (mg\%) & $126(37.9)$ & $120.6(32)$ & 0.9 \\
Total protein & $7.1(0.3)$ & $7.1(0.6)$ & 0.9 \\
FBS & $85(13.9)$ & $86.1(15)$ & 0.8 \\
Albumin & $3.5(0.3)$ & $3.7(0.6)$ & 0.08 \\
\hline
\end{tabular}

*Results are expressed as means and standard deviations

In the present study, increasing age was found to be associated with BAC. Women with BAC were significantly older than those without BAC in the present study. Maas et al [1] noted in their study that BAC was associated with increasing age, pregnancy and lactation but not with the traditional CVD risk factors. Kim et al [7] claim that Sickle and Galvin and Taskin et al [20] also found that at mammography, visible BAC are positively correlated with increased age. BACs were seen more frequently in postmenopausal women in other studies [7], while a study in Brazil by Ferreira et al [21] found that significantly more women with BAC had CVD compared to women who did not have BAC. This is however contrary to the finding in this study where only $3(8.8 \%)$ of the postmenopausal women had BAC.

Parity and breast feeding did not show any significant relationship with BAC in the present study. Previous studies have not been conclusive as to whether pregnancy and lactation may have any role in the calcification of other vascular beds besides breast arteries [1].

Vascular calcifications in the breast usually have a lipid component and resemble calcifications seen in other arteries [10]. The mechanism of deposition is still unknown. Oliveira et al [10] claim that when present, BAC was always bilateral. This may be a reflection of the atherosclerotic process and consequent vascular calcification affecting the whole arterial system. This was not true in this study as only $36.4 \%$ had bilateral BAC.

Although BAC was reported by Baum et al [8] as a sign of coexisting diabetes, none of the diabetics in this study had BAC. Findings in this study were also contrary to the study by Moshyedi et al [19], who reported that nearly all women in their study group younger than 59 years with BAC also had CAD and DM [7,11].

Studies have listed age, hypertension, hypercholesteraemia, DM and menopause as the risk factors for CVD

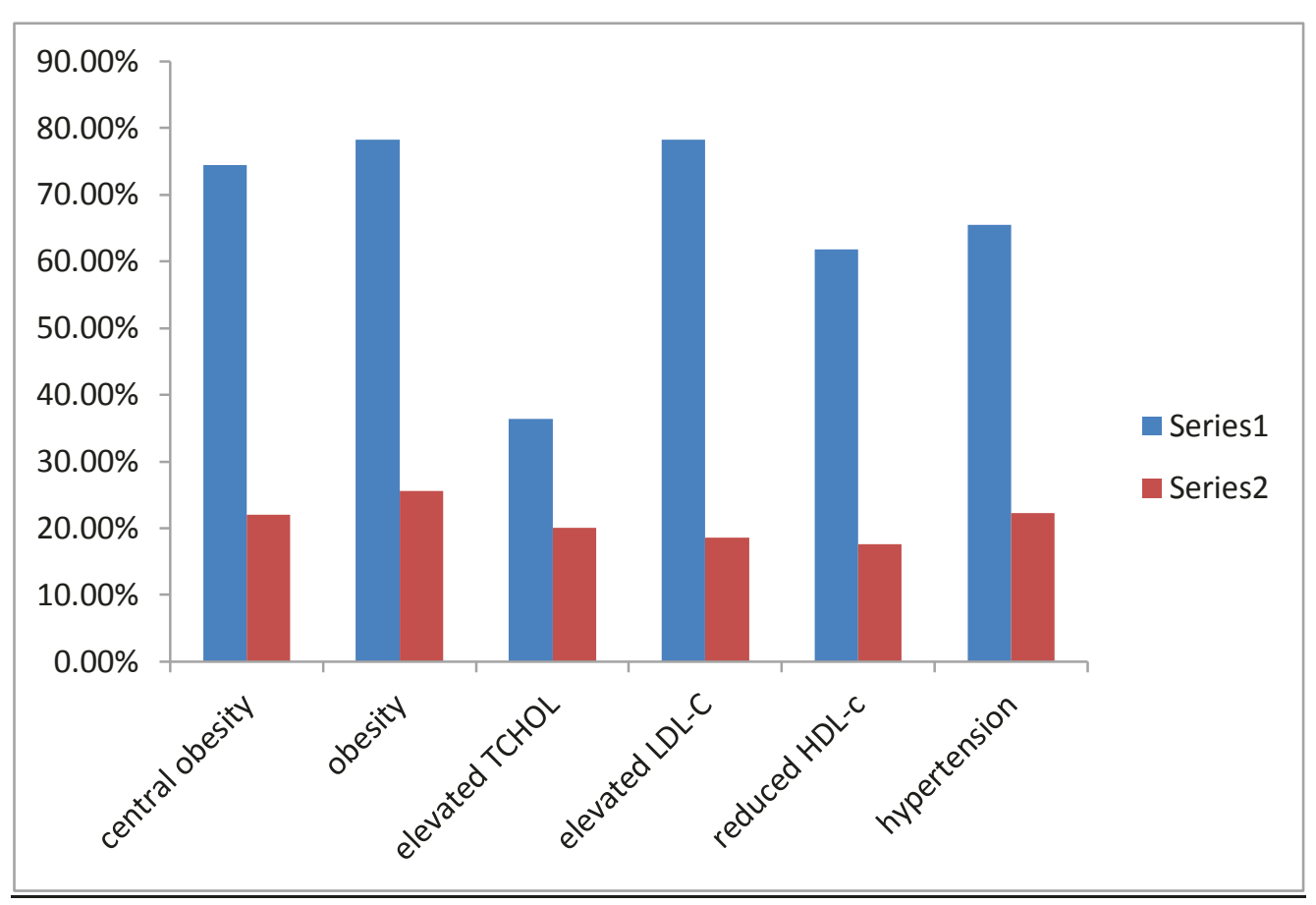

Figure 2 Distribution of cardiovascular risk factors in the study subjects and in those with vascular calcifications. Series 1: Proportion of study subjects with CVD abnormalities Series 2: Proportion of the subjects with stated CVD abnormalities that had mammary vascular calcification. 
Table 4 Possible Predictors of Vascular calcification

\begin{tabular}{cccc}
\hline Parameter & Odds ratio & $\mathbf{9 5 \%} \mathrm{Cl}$ & $\mathbf{p}$ value \\
\hline Central obesity & 0.7 & $0.1-5.9$ & 0.8 \\
Obesity & 0.9 & $0.01-2.5$ & 0.9 \\
Hypercholestolaemia & 1.2 & $0.26-6.4$ & 0.7 \\
Reduced HDL & 0.8 & $0.2-3.7$ & 0.8 \\
Elevated LDL & 0.3 & $0.05-2.5$ & 0.3 \\
\hline
\end{tabular}

[22] in BAC-positive populations. Age is the only significant factor that was found in the present study. This is similar to the findings by Kataoka et al [12].

The prevalence of BAC in this study is much higher than those of previous studies which were mostly done among the Caucasians $[10,12,13,22]$. The reason for the high prevalence in our environment is not known. Factors that may arise from racial differences between the subjects of this study (who are mostly black Africans) and those of other studies may be responsible. However, not much work has been done in this regard in Nigeria or Africa.

A study by Maas et al [1] has suggested a strong association between pregnancy, breast feeding and BAC. Pregnancy is associated with major changes in calcium metabolism to meet the high requirements for fetal growth and breast milk production. Pregnancy and breastfeeding induce transient hypercalcaemia. These may lead to calcium deposits in the breast arteries [1]. Contrary to the findings by Yildiz et al [6] that significantly linked increasing number of childbirths with $B A C$, there was no significant difference between the number of childbirths in subjects that had BAC and those that did not have BAC in this study. Our finding was also contrary to that of Maas et al [1].

The BMI was also not significantly higher in the subjects with BAC. This is contrary to the results from other studies [1-3]. We cannot explain the reason for this difference.

This study did not show any relationship between BAC and chronic diseases such as hypertension, and diabetes. This is in contrast with findings from studies by Kemmerem et al [2] and Oliveira et al [10].

\section{Conclusion}

We report the prevalence rate of BAC to be $20 \%$ in our environment. Increasing age was the only factor which we found to be related to its presence. All the other CVD risk factors that were found in previous literatures were not associated with the presence of BAC in this study. Therefore, BAC found in screening and diagnostic mammography may not be a marker for CVD in women in our environment. To the best of our knowledge, not much work has been done in Nigeria and Africa on this. It is recommended that further studies should be done to elicit the reasons for the high prevalence and the differences in the risk factors among Nigerians.

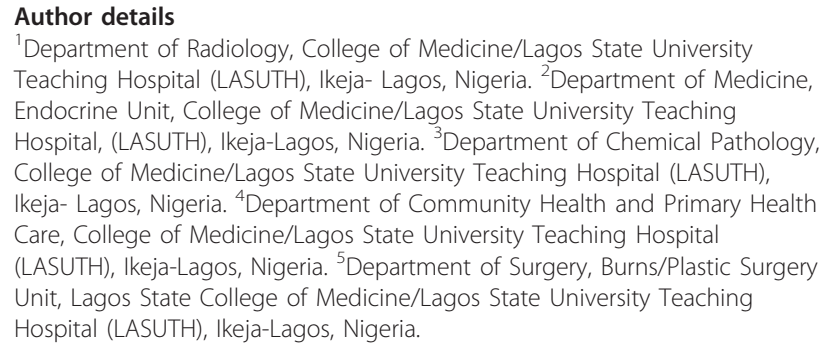

\section{Authors' contributions}

All authors have read and approved the final manuscript.

RAA Made substantial contribution to the conception and design of this study, acquisition and interpretation of data. She also helped in drafting and revising the script

OAO Contributed to data acquisition. Carried out the statistical analysis, point of care testing, sequence alignement and drafting of the script JAAO Contributed to data acquisition. Carried out the laboratory analysis and coordinated the laboratory works of the subjects

CEE Contributed to data acquisition. Coordination of the clinical aspect of the study, taking the weights, Blood pressure, BMI, E.T.C

IOF He helped in interpretation of data, drafting, revising of the script

\section{Competing interests}

The authors declare that they have no competing interests.

Received: 10 March 2011 Accepted: 20 June 2011

Published: 20 June 2011

\section{References}

1. Maas AHEM, van der Schouw YT, Beijerinck D, Deurenberg JJM, Mali WPTM, van DER Graaf Y: Arterial Calcifications seen on Mammograms: Cardiovascular risk factors, Pregnancy and Lactation. Radiology 2006, 240(1):33-38.

2. Kemmeren JM, van Noord PAH, Beijerinck D, Fracheboud J, Banga JD: Arterial calcification found on breast cancer screening mammograms and cardiovascular mortality in women. The DOM project. American Journal of epidemiology 1998, 147(4):333-341.

3. Tanya Washington Stephens, Gary J Whitman: Benign breast calcifications. 2009 [http://emedicine.medscape.com/article/347066-overview], eMedicine Specialities $>$ Radiology $>$ Breast.

4. Crystal P, Zelingher J, Crystal E: Breast arterial calcifications as a cardiovascular risk marker in women. Expert Rev Cardiovasc Ther 2004, 2(5):753-760.

5. Ratti C, Chiurlia E, Grimaldi T, Barbieri A, Romagnoli R, Modena MG: Breast arterial calcifications and coronary calcifications: a common link with atherosclerotic subclinical disease. Ital Heart J Suppl 2005, 6(9):569-574.

6. Yildiz S, Yildiz A, Ertug N, Kaya Ihsan, Yilmaz R, Yuksel E, Ziylan SZ: Association of breast arterial calcification and carotid intima-media thickness. Heart and vessels 2008, 23(6):376-382.

7. Kim H, Greenberg JS, Javitt MC: Residents' Teaching files. Breast calcifications due to Monckeberg medial calcific sclerosis. RSNA 1999.

8. Baum JK, Cornstock CH, Joseph L: Intramammary arterial calcification associated with diabetes. Radiology 1980, 136:61-62.

9. Fiuza Ferreira EM, Szeinfield J, Faintuch S: Correlation between intramammary arterial calcifications and CAD. Acta Radiol 2007, 14(2):144-150.

10. Oliveira ELC, Freitas-Junior R, Afiune-Neto A, Murta EFC, Ferro JE, Melo AFB: Vascular calcifications seen on mammography: An Independent factor indicating coronary artery disease. Clinics (Sao Paulo) 2009, 64(8):763-767.

11. Dale PS, Richards M, Mackie GC: Vascular calcifications on screening mammography identify women with increased risk of coronary artery disease and diabetes. Am J Surg 2008, 196(4):537-540. 
12. Kataoka M, Warren R, Luban R, Camus J, Denton E, Sala E, Day N, Khaw KT: How Predictive is breast arterial calcification of cardiovascular disease and risk factors when found at screening mammography? Am J Roentgenol 2006, 187(1):73-80.

13. Van Noord PA, Beijerinck D, Kemmeren JM, van der Graaf Y: Mammograms may convey more than breast cancer risk: breast arterial calcification and arteriosclerotic related diseases in women of DOM Cohort. Eur J Cancer Prev 1996, 5(6):483-487.

14. Lopez-Virella ML: Cholesterol determination in high-density lipoproteins separated by three different methods. Clin Chem 1977, 23:882-890.

15. Bucolo G, David H: Quantitative determination of serum triglycerides by the use of enzymes. Clin Chem 1973, 19:476-582.

16. Ogbera AO, Fasanmade OA, Chinenye S, Akinlade A: Characterization of lipid parameters in diabetes mellitus - a Nigerian report. Int Arch Med 2009, 20;2(1):19.

17. Alberti KG, Eckel RH, Grundy SM: Harmonizing the metabolic syndrome. A joint interim statement of the International Diabetes Federation Task Force on Epidemiology and Prevention. In Circulation. Volume 120. National Heart, Lung, and Blood Institute; American Heart Association; World Heart Federation; International Atherosclerosis Society; and International Association for the Study of Obesity; 2009:1640-1645.

18. Obesity and overweight: World Health Organization Facts sheet $\mathrm{N}^{\circ} 311$. 2011 [http://www.who.int/mediacentre/factsheets/fs311/en/].

19. Moshyedi AC, Puthawala AH, Kurland RJ, O'Leary DH: Breast arterial calcification: Association with coronary artery disease. Work in progress. Radiology 1995, 194:181-183.

20. Taskin F, Akdilli A, Karaman C, Unsal A, Koseogu K, Ergin F: Mammographically detected breast arterial calcifications: indicators for arteriosclerotic diseases. Eur J Radiol 2006, 60(2):250-255.

21. Ferreira JA, Pompej LM, Fernandes CE, Azevedo LH, Peixoto S: Breast arterial calcification is a predictive factor of cardiovascular disease in Brazilian postmenopausal women. Climacteric 2009, 12(5):439-440.

22. Rotter MA, Schnatz PF, Currier AA, O'Sullivan DM: Breast arterial calcifications (BACs) found on screening mammography and their association with cardiovascular disease. Menopause 2008, 15(2):276-281.

23. Sarrafzadegann N, Ashrafi F, Noorbakhsh M, Haghighi M, Sadeghi M, Mazaheri F, Asgari S, Akhayan A: Association of breast artery calcification with coronary artery disease and carotid intima-media thickness in premenopausal women. East Mediterr Health J 2009, 15(6):1474-1482.

doi:10.1186/1756-0500-4-207

Cite this article as: Akinola et al:: Mammograms and breast arterial calcifications: looking beyond breast cancer: a preliminary report. BMC Research Notes 2011 4:207.

\section{Submit your next manuscript to BioMed Central and take full advantage of:}

- Convenient online submission

- Thorough peer review

- No space constraints or color figure charges

- Immediate publication on acceptance

- Inclusion in PubMed, CAS, Scopus and Google Scholar

- Research which is freely available for redistribution

Submit your manuscript at www.biomedcentral.com/submit
Biomed Central 